\title{
Examining the possible impact of daily transport on depression among older adults using an agent-based model
}

Yong Yang ${ }^{1}$, Brent A. Langellier ${ }^{2}$, Ivana Stankov ${ }^{3}$, Jonathan Purtle ${ }^{2}$, Katherine L. Nelson ${ }^{2}$, Ana V. Diez Roux $^{3}$

\section{AFFILIATIONS}

${ }^{1}$ School of Public Health, University of Memphis

${ }^{2}$ Department of Health Management and Policy, Dornsife School of Public Health, Drexel University

${ }^{3}$ Urban Health Collaborative, Dornsife School of Public Health, Drexel University

Corresponding author:

Yong Yang

Yyang15@memphis.edu

339 Robison Hall

School of Public Health, University of Memphis

Memphis, TN, 38152 


\section{Examining the possible impact of daily transport on depression among 2 older adults using an agent-based model}

\section{Abstract}

$4 \quad$ Objectives: Daily transport may impact depression risk among older adults through several

5 pathways including facilitating the ability to meet basic needs, enabling and promoting contact with other

6 people and nature, and promoting physical activity (e.g. through active transportation such as walking or

7 walking to public transit). Both daily transport and depression are influenced by the neighborhood

8 environment. To provide insights into how transport interventions may affect depression in older adults,

9 we developed a pilot agent-based model to explore the contribution of daily transport and neighborhood

10 environment to older adults' depression in urban areas.

11 Method: The model includes about 18,500 older adults (i.e., agents) between the ages of 65 and

1285 years old, living in a hypothetical city. The city has a grid space with a number of neighborhoods and

13 locations. Key dynamic processes in the model include aging, daily transport use and feedbacks, and the

14 development of depression. Key parameters were derived from US data sources. The model was

15 validated using empirical studies.

16 Results: An intervention that combines a decrease in bus fares, shorter bus waiting times, and

17 more bus lines and stations is most effective at reducing depression. Lower income groups are likely to be

18 more sensitive to the public transit-oriented intervention.

19 Conclusion: Preliminary results suggest that promoting public transit use may be a promising

20 strategy to increase daily transport and decrease depression. Our results may have implications for

21 transportation policies and interventions to prevent depression in older adults.

\section{Keywords}

23 Depression, older adults, agent-based model, daily transport, aging

\section{$24 \quad$ Funding}

This study was supported by the European Union Horizon 2020 Programme under grant

27 not necessarily reflect the Commission's views and in no way anticipates the Commission's future policy

28 in this area.

\section{Disclosure statement}

No financial disclosures were reported by all authors of this paper. 


\section{1. Introduction}

Mental health is a particular concern of the growing aging population living in cities across the world (Beard \& Bloom, 2015; Reynolds et al., 2012). Older adults are at an increased risk of clinically significant depressive symptoms (World Health Organization, 2013). In interaction with other health issues including comorbid physical health problems and physical disability (Fiske, Wetherell, \& Gatz, 2009;

6 J. Katon, 2011), depression may have more serious consequences in older adults than in younger groups. Depression risk among older adults is influenced by factors at the individual (e.g., physical activity, income), interpersonal (e.g., loneliness, social support), neighborhood (e.g., access to green space), health care system, and societal (e.g., stigma) levels (Martin G. Cole \& Nandini Dendukuri, 2003). An important factor that may influence depression risk among the elderly and that is amenable to public policy is daily transport (Choi \& DiNitto, 2016), defined as both active (e.g., walking) and passive (e.g., car, bus) transportation. Similar to the general population, older adults' daily transport is associated with household income, driver status, car ownership and household vehicle count (Pucher, Buehler, Merom, \& Bauman, 2011; Pucher \& Renne, 2003). However, compared to younger populations, older adults tend to take fewer trips, travel shorter distances, have smaller activity zones, and engage in a larger share of nonwork trips. Furthermore, this decrease in daily transport activities is even more pronounced in older women and older adults with medical conditions (Collia, Sharp, \& Giesbrecht, 2003; Horner, Duncan, Wood, Valdez-Torres, \& Stansbury, 2015).

Daily transport may impact depression risk and other mental health outcomes among older adults through several pathways. First, daily transport is indispensable to meet most basic needs (e.g., grocery shopping, access to health care services), and the failure to meet basic needs as a result of unmet daily transport may increase the risk of depression among older adults (Choi \& DiNitto, 2016). Second, daily transport enables and promotes contact with other people and nature, which have positive effects on overall mental health and wellbeing (Kawachi \& Berkman, 2001; Ulrich et al., 1991). Older adults with limited daily transport are more likely to live in isolation and thus less likely to participate in meaningful social and cultural activities and maintain supportive social networks (Musselwhite, Holland, \& Walker, 2015). Additionally, as a source of physical activity, active transportation has a protective effect on mental health and depression (Barbour \& Blumenthal, 2005; De Mello et al., 2013; Mammen \& Faulkner, 2013). Transitions from a physically active state to an inactive one, which are increasingly common as older adults age, are associated with major depressive episodes (Patten, Williams, Lavorato, \& Eliasziw, 2009).

Daily transport and depression are both influenced by the neighborhood environment (Julien, influence older adult's overall level of mobility as well as the types of travel modes they use most frequently (e.g., walking, cycling, public transit) (Rosso et al., 2011; Saelens \& Handy, 2008; Winters, Brauer, Setton, \& Teschke, 2010). Compared with younger adults, older adults' daily transport may be more impacted by the neighborhood environment because of increased time spent in their neighborhoods (Glass \& Balfour, 2003). Furthermore, cognitive and physical constraints may make older 
crosswalks may be barriers to walking). In addition, neighborhood characteristics such as neighborhood crime, unsafe traffic, social cohesion and access to recreational facilities may be associated with depression independent of transportation and walkability (Elliott, Gale, Parsons, Kuh, \& Team, 2014; Ivey et al., 2015; Julien et al., 2012; Mair, Roux, \& Galea, 2008; Richardson, Westley, Gariépy, Austin, \& Nandi, 2015). Overall, older adults may be more vulnerable to neighborhood factors than younger adults.

Policies that promote public transport use may increase both daily transport and overall physical activity among older adults. Despite longer durations than automobile trips, public transport use has a number of benefits (e.g., free time on board, and reduced gasoline consumption, congestion, and land for parking) and may be the only feasible option for older adults who are more likely to have a driving limitation. Walking is probably the most common mode for accessing the public transit. An inability to safely walk from home to a nearby transit stop has been reported as a significant barrier to public transportation ridership among older people (Hess, 2009). Thus walking-friendly environments, especially in the vicinity of transit stops and stations are critical for both daily transport and physical activity.

The neighborhood environment, daily transport, and depression are interrelated. These interrelations may involve feedbacks, dependencies, and conditional effects. Understanding the impact of policies may require understanding these dynamic relationships. Agent-based modeling ( $A B M)$ has gained increasing attention in public health because it captures the dynamic interactions between multi-level factors and accounts for feedback mechanisms among individuals and between individuals and their environment (Luke \& Stamatakis, 2012; Nianogo \& Arah, 2015). A small number of ABMs have been used to examine mental health issues (Cerda, Tracy, Keyes, \& Galea, 2015; Kalton et al., 2016; Lyon, Maras, Pate, Igusa, \& Stoep, 2016; Stephen J. Mooney \& Abdulrahman M. El-Sayed, 2016). However, to our knowledge, only one study has used ABM to explore social determinants of depression, focusing on the role that an individual's body weight, social norms, and social isolation play in shaping depression risk (S. J. Mooney \& A. M. El-Sayed, 2016). No studies have used ABM to assess the role that daily transport or physical activity play in shaping mental health.

We developed a pilot ABM to explore the contribution of daily transport and the neighborhood environment on older adults' depression in urban areas. The primary research aim was to examine the possible influence of policies seeking to improve both public transportation and the walkability of neighborhood environments on depression prevalence among older adults.

\section{Methods}

\subsection{Model overview}

The ABM includes about 18,400 agents, each representing an older adult between 65 and 85 years old living in a hypothetical city. People older than 85 were excluded because the empirical data sources used for model development generally did not include data on this age group. The model runs in discrete time with each time step representing one year. The ABM explicitly incorporates dynamic processes including aging, transport use, and depression development (Figure 1). The ABM was adapted from two previously published models (Yang et al., 2015; Yang, Diez Roux, Auchincloss, Rodriguez, \& 
1 Brown, 2011) and developed using Java and Repast (a free and open-source agent-based modeling and

2 simulation toolkit) ("The Repast Suite," 2017).

3 The model environment represents a city of $64 \mathrm{~km}^{2}(8 \mathrm{~km}$ by $8 \mathrm{~km})$ with an $800 * 800$ grid space,

4 where each cell of size $10 \mathrm{~m} * 10 \mathrm{~m}$ is either occupied by a location or is empty. The location can be a

5 residence, a location for basic needs (e.g. shop), or a location for social activities (e.g. social place,

6 restaurant, or bar). Figure 2 shows the spatial display of the hypothetical city. The city has 400 equally-

7 sized neighborhoods, each composed of $40 * 40$ cells. Each neighborhood is assigned three variables

8 including safety (e.g. neighborhood crime levels), walkability (here defined as pedestrian friendliness),

9 and environmental depression risk (EDR). We defined EDR as a variable that represents all unmeasured

10 dimensions of a neighborhood that are likely to impact depression risk (e.g., neighborhood social

11 cohesion, green space, aesthetic, blight) that are not captured in the safety and walkability variables. The

12 value of each neighborhood variable ranges between 0 and 1 , wherein 1 indicates the based on the safest

13 for safety, the most walking friendly for walkability, and the lowest depression risk for EDR. The city has a

14 symmetrical public transport network. Three east-west bus lines and three north-south bus lines cross

15 each other with $2 \mathrm{~km}$ distances between bus lines. Each bus route covers $4 \mathrm{~km}$ with bus stops at 400-

16 meter intervals, consistent with US data (distances between bus stops in the range of 200-600 meters

17 (Ammons, 2001)). Altogether the city center has 57 bus stops. There is no public transport network

18 outside of the city center.

Each time step (one year), 1,000 older adults of age 65 years (as 500 households, each with one

21 males and females. However, during the course of the simulation and as a result of the empirically-

22 informed mortality rates which vary by age and gender (Table 1), the population of older adults in the

23 model becomes disproportionately more female in line with real world trends. Upon entry into the model,

24 adults in each household are assigned to a residence and each employed adult is randomly assigned to a

25 workplace. Each adult is assigned properties including depression status, income level, driver's license

26 status, car ownership status, and employment status. The distribution of these variables is based on

27 national prevalence data from the US (see Table 1). Each adult is assigned attitudes towards driving,

28 public transit use, and walking using a random draw from a uniform distribution ranging between 0 and 1.

\subsection{Dynamic processes}

\subsubsection{Aging and Events}

At each step, all existing adults age one year. Adults leave the model once they reach 85 years or if they die. At Step 20 (when the group of older adults who entered the ABM at Step 1 reach 85 years), the model reaches an equilibrium state with the total living population stable at roughly 18,500 individuals aged between 65 and 85 years with a pyramid structure.

Events (i.e., death, retirement, and loss of driver's license) occur at each time step based on ageand gender-specific probabilities derived from empirical data sources (see Table 1). For example, the probability that a 75-year-old female in the model will lose her driver's license is based on data for 
1 females of the same age, as informed by data from the U.S. Census Bureau (US Census Bureau, 2017).

2 Similarly, each adult may switch between having or not having depression at each time step with a

3 probability calculated based on their current depression status, age, gender, daily transport, and

4 neighborhood environment (see Subsection 2.2.3 below). Similarly, older adults' transition out of the

5 workforce is informed by data stratified by age and gender (see Table 1).

\subsubsection{Transport and feedback}

For each time step, we simulate each older adult's transport within a typical week. Empirical studies have reported that the average travel time budget across population samples is approximately 1.1 hours per person per day (Schafer \& Victor, 2000; Zahavi \& Talvitie, 1980). Compared with the younger adult population, older adults tend to make fewer trips (Collia et al., 2003; Horner et al., 2015). The city in our model is relatively small and our model only captures travel within the city (i.e., all travel outside of the city is ignored by the model and thus should be deducted from the travel time budget). Based on these considerations we set a total travel time budget of 3.5 hours per week for each older adult, and assumed this travel time budget does not change with age.

Adults in the model engage in travel for four purposes: 1) work, 2) basic needs, 3) social activities, and 4) walking for leisure. It is reasonable that a person will prioritize travel for work and basic needs over travel for social activities. Within a typical week, an older adult will travel by the following sequence until the travel time budget is used up: five trips for work (if the person has a job), seven trips for basic needs (one trip per day), and seven trips for social activities. If there is still travel time budget remaining, individuals will alternate travel for basic needs and for social activities until all time budget is used up. Older adults also have the option of walking for leisure around their household but this is not counted in the total travel time budget.

For each trip, an older adult chooses between three travel modes: (1) driving, (2) public transportation, or (3) walking. This choice is made by evaluating the relative utility of each travel mode; where modes with higher utility have a greater likelihood of being selected. The utility of a given travel mode is positively associated with an individual's attitudes toward this mode and negatively associated with the cost of travel (e.g., fuel price, bus fee, parking fee, and travel time cost). Attitude towards walking is updated through a feedback mechanism. The idea is that a positive past experience of travel using a certain travel mode may positively increase the attitude towards this mode, and vice versa. The attitude towards walking is affected by the safety and walkability along the travel path. For simplicity, the attitudes towards public transit and towards driving are assumed constant. See Yang et al.'s ABM for detailed information relating to the formula on travel mode choice and feedback (Yang et al., 2015).

\subsubsection{Depression}

We operationalized depression as clinically significant depressive symptoms (i.e., a score $\geq 4$ on the Center for Epidemiologic Studies Depression Scale-8) (West, Cole, Goodkind, \& He, 2014). Although clinically significantly depressive symptoms are less severe than major depressive disorder, which meets full DSM criteria and is diagnosed through a structured clinical interview, having these symptoms 
increases the risk for adverse outcomes among older adults in a similar way that a diagnosis of major depression does (Meeks, Vahia, Lavretsky, Kulkarni, \& Jeste, 2011). At each time step, every adult has the opportunity to transition from their current status. The transition probability is a function of two processes. The first is the aging process where the probability of changes are based on age and gender (Table 1). The second process is how daily transport and neighborhood environment influence depression state using the following formula (equation 1).

$$
P=w_{t}\left(\frac{t}{T}-1\right)+w_{d}\left(\frac{d}{D}-1\right)+w_{e}\left(1-\frac{e}{E}\right)
$$

Where $\mathrm{P}$ is the probability of transitioning and $t, d, e$ are an older adult's total non-work trips, total walking distance, and EDR in the neighborhood during the past week, respectively, and where $T, D$, and $E$ are corresponding threshold constants which were assigned based on empirical data. $w_{t}, w_{t}$, and $w_{t}$ are weights with the sum equaling to one. These weights indicate the magnitude of the influence of total non-work trips (for simplicity, we assume that only non-work trips influence depression as these types of trips occur more routinely among older adults than non-work trips), total walking distance, and EDR on depression status. Here, $w_{t}=w_{t}=w_{t}=1 / 3$. If $P>0$, the older adult has a probability $P$ of changing status from being depressed to not depressed. If $P<0$, the older adult has a probability of $P$ to transfer from not being depressed to depressed. If $P=0$, the adult remains in the same status.

\subsection{Baseline scenario and model validation}

The baseline scenario reflects the segregation patterns by income level present in many US cities where lower-income households are more likely to be located in the center of the city and higher-income households are more likely to be located in the periphery (Berube, Katz, \& Lang, 2003 ). At the same time, evidences show that neighborhood poverty is associated with crime (Graif, Gladfelter, \& Matthews, 2014; Hsieh \& Pugh, 1993). Poor neighborhoods tends to lack amenities that are beneficial to mental health (Joshi et al., 2017). As Figure 2 shows, the density of non-residential locations decays outwards from the center of the city, such that more non-residential locations are in the core and fewer non-residential locations are in the periphery. At the same time, EDR and safety decay inwards towards the center of the city, such that there is lower EDR and safety in the core and higher EDR and safety in the periphery. We assume no spatial pattern of walkability.

The model was validated by comparing the model results with the general empirical patterns in the US including the variation of depression by gender, age, and income level. As our simulated results show in Figure 3, adults that are female, older, or with lower income level have a higher prevalence of depression than adults who are male, younger, or with higher income level, respectively. This is consistent with US national patterns (Dunlop, Song, Lyons, Manheim, \& Chang, 2003; Steffens, Fisher, Langa, Potter, \& Plassman, 2009; Thielke, Diehr, \& Unützer, 2010; West et al., 2014).

\subsection{Scenario analysis}

We explored three categories of interventions to decrease depression. The first intervention aimed to promote walking by increasing the walkability and safety of neighborhoods across the whole city. This was implemented in a scenario W (for walking). In this scenario, for all zones across the city, 
1 walkability and safety were increased to be the maximum value in the model (i.e., 1). Second, an

2 intervention promoting public transit through decreased bus fares (change from one dollar per trip to be

3 free for older adults) and bus waiting times (decreased from 6 minutes to be 3 minutes per trip) was

4 explored. This was implemented in a scenario $\mathrm{F}$ (for bus fare). Third, an intervention promoting public

5 transit through the simultaneous addition of bus lines (an increase from 6 lines to 14 lines) and bus

6 stations (the total number of stations were increased from 57 to be 385 and the distance between

7 stations were decreased from 400 meters to be 200 meters) was simulated. This was implemented in a

8 scenario L (for bus line). We also explored the combinations of above three interventions.

\section{3. Results}

Figure 4 shows the variation of depression prevalence by age, in the context of several interventions. Overall, the depression prevalence increases with age. Compared with the baseline scenario, the depression prevalence in scenarios $\mathrm{W}, \mathrm{F}, \mathrm{L}, \mathrm{W}+\mathrm{L}$, and $\mathrm{W}+\mathrm{F}$ decreases mildly, and among them, scenario $F$ (i.e., decrease bus fare and bus waiting time) is relatively more effective than others. The most effective scenarios are $\mathrm{F}+\mathrm{L}$ and $\mathrm{W}+\mathrm{F}+\mathrm{L}$.

Figures 4 shows the variation of depression percentage, total trips, total bus trips, and total walking distance, by age and income level, under baseline and $\mathrm{F}+\mathrm{L}$ scenarios . In general, under all four scenarios, higher income groups have lower rates of depression, more total trips, fewer bus trips, and smaller walking distances than lower income groups. Older adults have higher depression prevalence and fewer total trips than younger adults. The pattern of total trips and active travel by income is consistent with empirical data (Quinn, Jakicic, Fertman, \& Barone Gibbs, 2016) further validating our model. Specifically, $\mathrm{F}+\mathrm{L}$ is the most effective scenario in decreasing depression prevalence, particularly among lower income groups. Moreover, the depression prevalence gap among different income groups is much narrower under $\mathrm{F}+\mathrm{L}$ than the baseline scenario. Similarly, the total trips are significantly higher under the $\mathrm{F}+\mathrm{L}$ scenario compared to baseline, and the increase is again much larger for lower income groups.

Additionally, the total walking distance in Scenario $\mathrm{F}+\mathrm{L}$ decreases slightly for all income levels relative to the baseline scenario. As shown by Figure 6 , scenario $F$ (i.e., decrease in bus fare and bus waiting time) is particularly effective in increasing total bus trips for lower income groups 1 and 2 while scenario L (i.e., add bus lines and stations) is moderately effective in increasing total bus trips for all income groups. The $\mathrm{F}$ $+\mathrm{L}$ scenario displays a synergistic effect in increasing bus trips, as the increase of bus trips when $\mathrm{F}$ and $\mathrm{L}$ are combined is larger than the sum of the individual effects of scenarios $F$ and $\mathbf{L}$.

\section{Discussion}

By representing a plausible dynamic pathway of how the daily transport and neighborhood environment jointly influence depression among older adults, the model allows us to explore the possible impact of various transportation and built environment interventions on depression. As our results show, an intervention that combines a decrease in bus fare and bus waiting time with the addition of bus lines and stations is most effective. Promoting public transit use is a promising strategy by which to increase older adults' daily transport and decrease depression prevalence, particularly among lower income 
1 groups which appear more sensitive to public transit-oriented interventions. Our results may have

2 implications for transportation policies and highlight possible unintended benefits of transportation and

3 built environment intervention for older adults' depression risk.

$4 \quad$ It may be counterintuitive that increasing neighborhood walkability and safety (scenario W) has

5 almost no effect on depression prevalence. A possible explanation for this finding may be that increases

6 in walkability and safety lead to increases in people's favorable attitude towards walking, which in turn

7 makes them more likely to choose walking over other travel modes. However, for most trips, except very

8 short trips, the trip duration is longest when walking is the chosen travel mode. One implication of this

9 and the fact that the model assumes a fixed daily travel time budget is that an increase in the frequency

10 of daily walking trips results in a faster depletion of the daily travel time budget. This ultimately limits the

11 number of non-work trips that may be taken. Since both the number of non-work trips and the total

12 walking distance directly influence depression, the reduction in the total number of trips may outweigh

13 the beneficial effects of walking.

In contrast, using public transit typically takes less time than walking as long as buses arrive

frequently. The reduction in bus waiting time, which is achieved by adding bus lines and bus stations, increases the relative advantage of using public transit compared to driving. Scenarios that combine $F$ and $L$ show the greatest reduction in prevalence of depression for the lower income groups. This is because lower income groups are more sensitive to bus fare decreases. Therefore, while scenario $\mathrm{F}+\mathrm{L}$ increases total non-work trips traveled by bus, these trips do not decrease overall walking distances because people still need walk to the bus stop in order to access the service.

ABM, as a modelling process, could include a finite number of key elements. Our decisions about which variables to include were guided by our judgement and some potentially important features and associations among features may be neglected. For example, our model did not cover an older adult's physical health status despite the associations between physical health status, the aging process, daily transport, and depression (Yuri \& Brenda, 2014). Furthermore, the processes leading to the development of depression are grossly simplified. The values for some parameters (e.g., the total travel time budget) may be arbitrary to some extent. Other features excluded from this model include carpooling, transportation provided by family and friends, the impact of weather on travel decision, the length of time older adults have resided in their neighborhood, ride-sharing technologies like Uber and Lyft, and driverless vehicles. More empirical studies are needed to provide additional rationales for rules and mechanisms, as well as, more precise values for parameters (e.g., travel time budget among older adults).

Despite the above limitations, our study can help deepen our understanding of the interrelated processes that link aging, daily transport and depression risk among older adults. We view this simple, abstract model as a tool for preliminary exploration and insight and the basis for developing more sophisticated modeling approaches that can inform how urban policies may impact mental health among older adults. For example, an adapted version of the model could be used to study depression disparities by income level, because household income impacts travel mode choice, the availability of having a car at 38 home, and neighborhood characteristics. 
Our preliminary findings highlight the potential importance of providing and improving public

2 transit for older adults. High-quality public transit is a promising strategy because it can increase the

3 number of trips without excessive increase in the time needed to travel and promotes walking. In

4 addition, public transit is crucial for those who do not have a car or are increasingly unable to drive as

5 they age (Choi \& DiNitto, 2016). However, recent data shows that only $2.3 \%$ of all trips among US older

6 adults use public transit (Lynott \& Figueiredo, 2011). Barriers to public transit use among older adults

7 include concerns about safety; the reliability, comfort, and habitual dependence on driving; the

8 walkability of the neighborhood environment; and lack of public transportation availability (Peck, 2010;

9 Transportation for America, 2011). The reduction of these barriers in order to increase public transit use

10 among older adults will require multiple strategies and investments.

11 Our study is not intended to be definitive or account for the complete range of factors that

12 influence depression risk among older adults. Rather, the $A B M$ allows us to integrate knowledge from

13 different fields and combine data from various sources. The ABM helps identify critical gaps in knowledge

14 and data by "forcing" investigators to make tacit knowledge explicit and specify the mechanisms

15 generating key "stylized facts" of interest. For example, during the model process, we found that the

16 existing knowledge and data on the inter-relationships between the dynamic processes of aging,

17 depression, and environmental influence are extremely limited. Iterative interactions between ABMs and

18 empirical research - wherein ABM integrate existing knowledge and also prompt the production of new

19 knowledge - should be encouraged. 
Table 1. Individual and household level parameters and supporting data sources

\begin{tabular}{|c|c|c|c|}
\hline Parameters & Value range & $\begin{array}{l}\text { Prevalence at age } 65 \text { and data } \\
\text { source }\end{array}$ & $\begin{array}{l}\text { Parameter for change over time } \\
\text { (e.g., incidence) and data source } \\
1\end{array}$ \\
\hline Age & $65-85$ & & $\begin{array}{l}\text { Mortality rates from National } \\
\text { Vital Statistics Reports, } 2014 \\
\text { (Kochanek, Murphy, Xu, \& } \\
\text { Tejada-Vera, 2016) }\end{array}$ \\
\hline Gender & Male/female & $50 \%$ male, and $50 \%$ female & No change \\
\hline Income level & $1-5$ & $\begin{array}{c}\text { Evenly distributed from } 1 \\
\text { (lowest) to } 5 \text { (highest) }\end{array}$ & No change \\
\hline $\begin{array}{r}\text { Depression } \\
\text { (clinically significant } \\
\text { depressive } \\
\text { symptoms, score of } \\
\geq 4 \text { on the Center for } \\
\text { Epidemiologic } \\
\text { Studies Depression } \\
\text { Scale-8) }\end{array}$ & Yes/no & $\begin{array}{l}\text { 10\% of males; } 17.5 \% \text { of females. } \\
\text { From Federal Interagency } \\
\text { Forum on Aging-Related } \\
\text { Statistics, 2012; and Health and } \\
\text { Retirement Study, 2008 (West } \\
\text { et al., 2014) }\end{array}$ & $\begin{array}{l}\text { Incidence rate and probability } \\
\text { of keeping depressed. From } \\
\text { Cardiovascular Health Study } \\
\text { (Thielke et al., 2010) }\end{array}$ \\
\hline Driver's license & Yes/no & $\begin{array}{c}\text { 95\% of males; } 89 \% \text { of females. } \\
\text { US Census, } 2014 \text { (US Census } \\
\text { Bureau, 2017) }\end{array}$ & $\begin{array}{c}\text { Incidence rate of losing driver's } \\
\text { license. From } 2014 \text { US Census } \\
\text { (US Census Bureau, 2017) }\end{array}$ \\
\hline Employment status & Yes/no & $\begin{array}{l}44 \% \text { of males and } 33 \% \text { of } \\
\text { females. From the Health and } \\
\text { Retirement Study (Karp, 2007) }\end{array}$ & $\begin{array}{l}\text { Incidence rate of losing job. } \\
\text { From Health and Retirement } \\
\text { Study (Karp, 2007) }\end{array}$ \\
\hline Car ownership & Yes/no & $\begin{array}{l}\text { Prevalence by income quintile } \\
\text { (highest to lowest): } 26.6 \% \text {, } \\
6.5 \%, 2.2 \%, 1.3 \% \text {, and } 2.0 \% \text {. } \\
\text { From } 2009 \text { National Household } \\
\text { Travel Survey (NHTS, 2017) }\end{array}$ & No change \\
\hline
\end{tabular}

\footnotetext{
${ }^{1}$ All incidence data are age- and gender-specific
} 
Household income

level, and car ownership

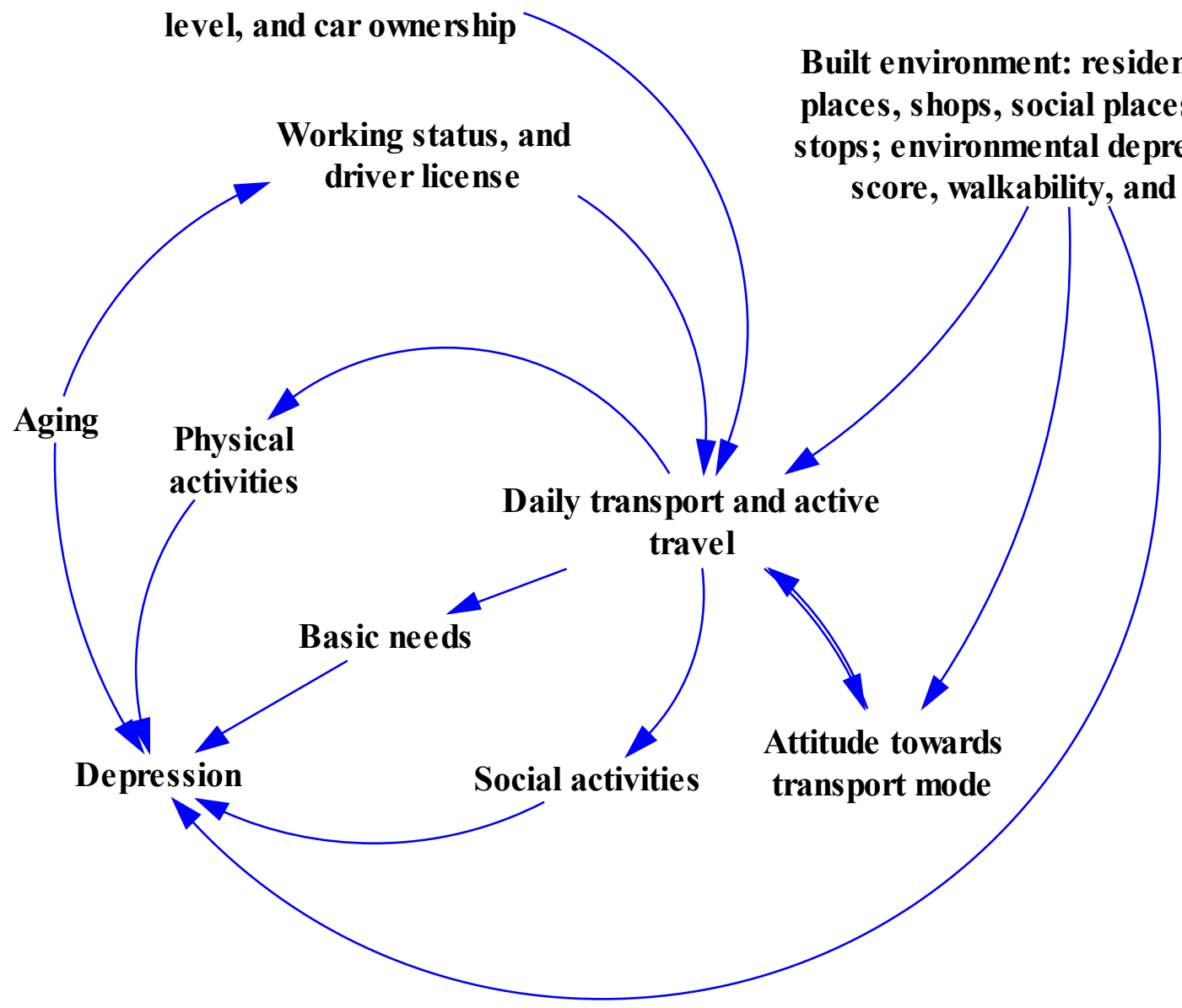

Figure 1. Framework for an agent-based model of daily transport and depression among older adults. 


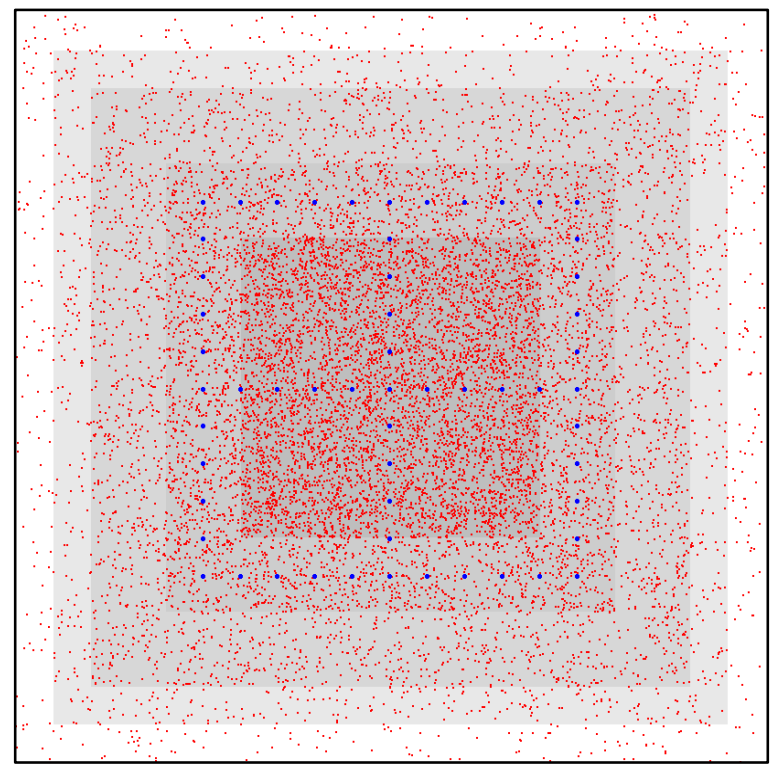

2 Figure 2. Spatial display of the Baseline scenario. Red dots are locations related to basic needs or social 3 activities, while the blue dots represent transit stations. Residences are not displayed. The city is divided 4 into five concentric zones. Zone 1 is represented by the lightest shade of grey, while zone 5 appears 5 darkest in the center of the square. The income level of residents, environmental depression risk (EDR), 6 and safety decay as one moves inwards from the periphery toward the city center. 


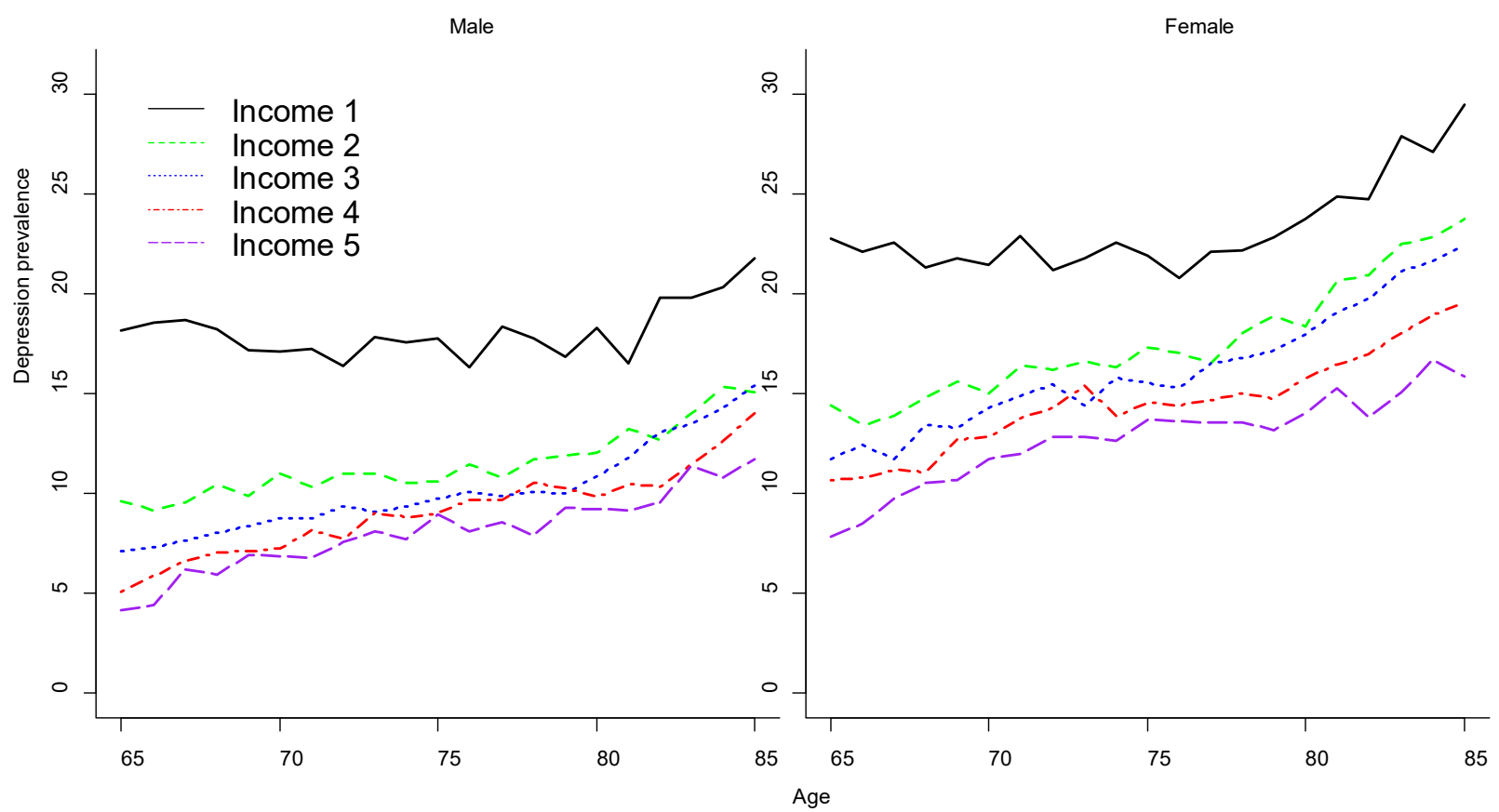

2

3 Figure 3. Prevalence of depression by age, gender, and income level in the Baseline scenario. 


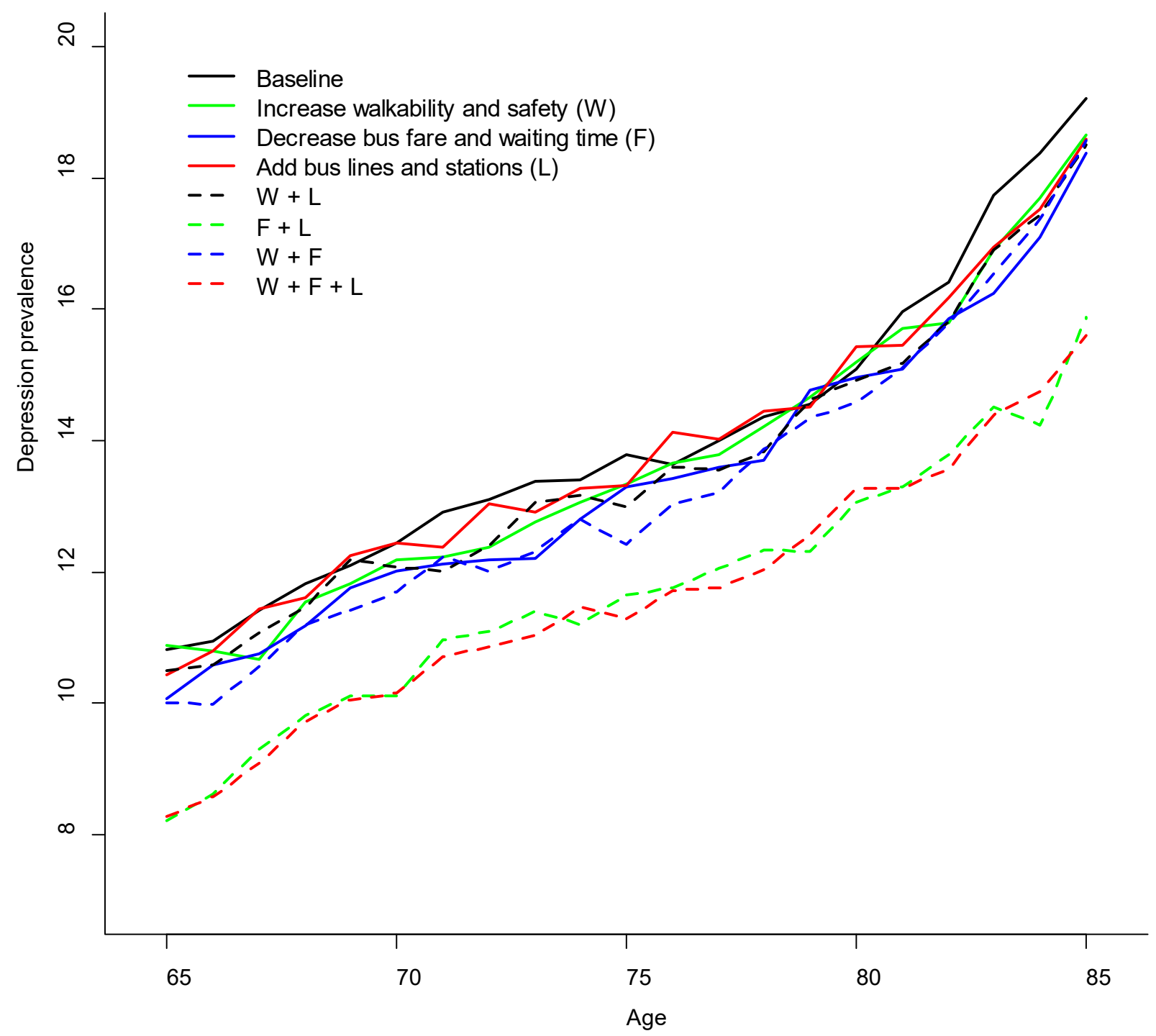

1

Figure 4. Prevalence of depression by age, in eight different scenarios, including Baseline, Increase walkability and safety (W), Decrease bus fare and waiting time (F), Add bus lines and stations (L), Increase walkability and safety + Add bus lines and stations $(W+L)$, Decrease bus fare and waiting time + Add bus lines and stations $(F+L)$, Increase walkability and safety + Decrease bus fare and waiting time $(W+F)$, and Increase walkability and safety + Decrease bus fare and waiting time + Add bus lines and stations $(W+F+L)$. 


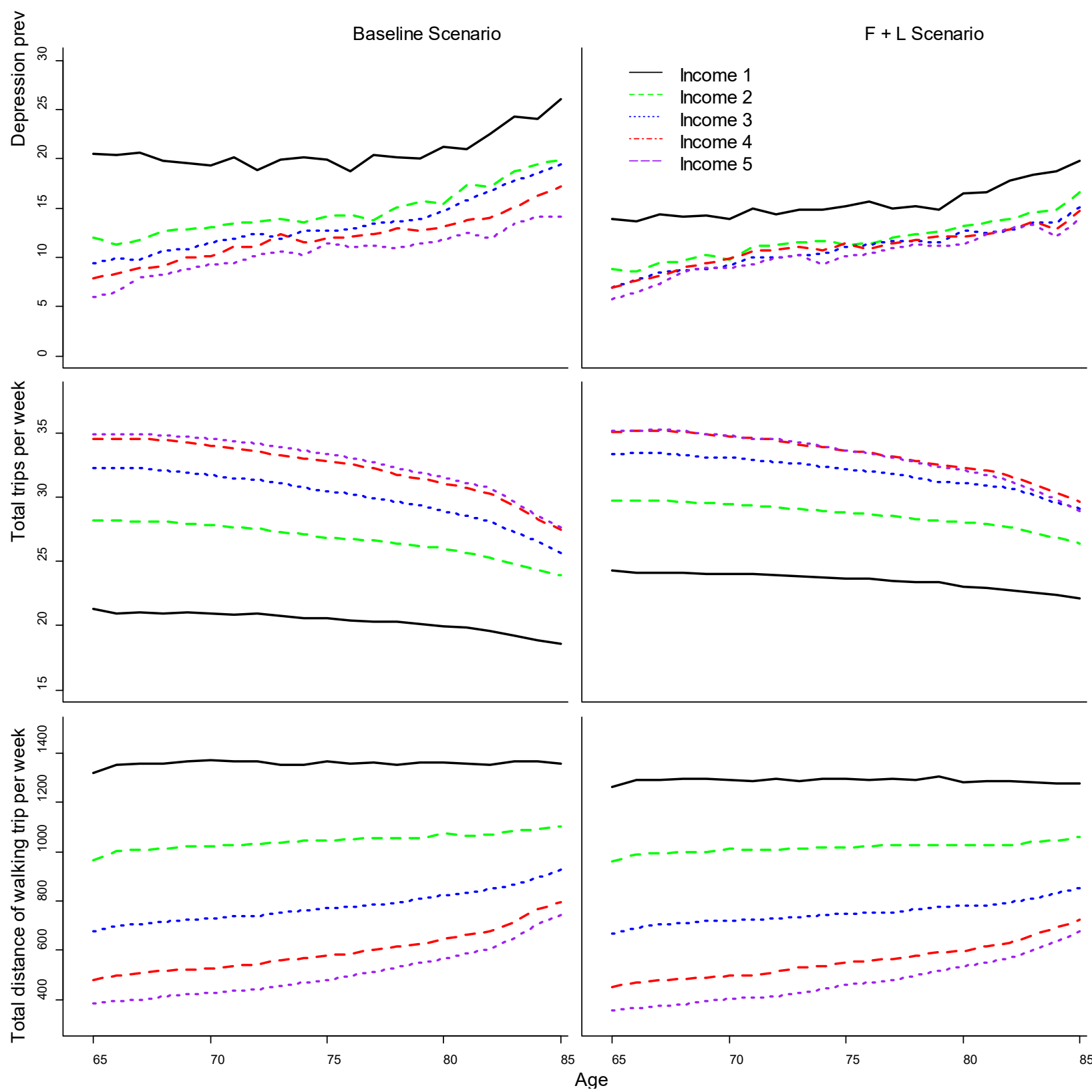

Figure 5. Prevalence of depression, total trips per week, and total distance of walking trips per week, for the Baseline, and Decrease bus fare and waiting time + Add bus lines and stations $(F+L)$ scenarios. 


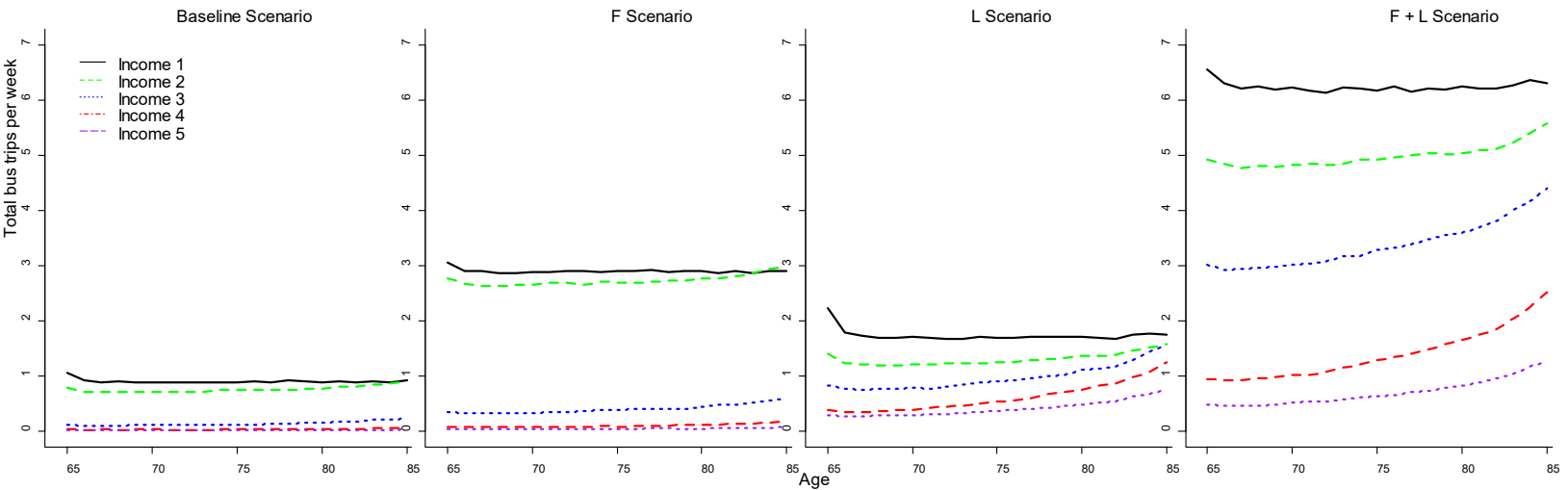

$2 \quad$ Figure 6. Total bus trips per week, in four scenarios, including Baseline, Decrease bus fare and waiting 3 time $(F)$, Add bus lines and stations ( $L$ ), and Decrease bus fare and waiting time + Add bus lines and stations $(\mathrm{F}+\mathrm{L})$ scenarios. 
Ammons, D. N. (2001). Municipal benchmarks: Assessing local performance and establishing community standards (2nd ed.). Thousand Oaks, CA: Sage Publications.

Barbour, K. A., \& Blumenthal, J. A. (2005). Exercise training and depression in older adults. Neurobiology of Aging, 26(1), 119-123. doi: 10.1016/j.neurobiolaging.2005.09.007

Beard, J. R., \& Bloom, D. E. (2015). Towards a comprehensive public health response to population ageing. The Lancet, 385(9968), 658-661. doi: 10.1016/S0140-6736(14)61461-6

Berube, A., Katz, B., \& Lang, R. E. (2003 ). Redefining Urban and Suburban America: Evidence from Census 2000 (Vol. 2). Washington, D.C.: Brookings.

Cerda, M., Tracy, M., Keyes, K. M., \& Galea, S. (2015). To Treat or to Prevent? Reducing the Population Burden of Violence-related Post-traumatic Stress Disorder. Epidemiology, 26(5), 681-689.

Choi, N. G., \& DiNitto, D. M. (2016). Depressive Symptoms Among Older Adults Who Do Not Drive: Association With Mobility Resources and Perceived Transportation Barriers. The Gerontologist, 56(3), 432-443. doi: 10.1093/geront/gnu116

Collia, D. V., Sharp, J., \& Giesbrecht, L. (2003). The 2001 National Household Travel Survey: A look into the travel patterns of older Americans. Journal of Safety Research, 34(4), 461-470. doi: http://dx.doi.org/10.1016/j.jsr.2003.10.001

De Mello, M. T., Lemos, V. d. A., Antunes, H. K. M., Bittencourt, L., Santos-Silva, R., \& Tufik, S. (2013). Relationship between physical activity and depression and anxiety symptoms: A population study. Journal of Affective Disorders, 149(1-3), 241-246. doi: http://dx.doi.org/10.1016/i.jad.2013.01.035

Dunlop, D. D., Song, J., Lyons, J. S., Manheim, L. M., \& Chang, R. W. (2003). Racial/Ethnic Differences in Rates of Depression Among Preretirement Adults. American Journal of Public Health, 93(11), 1945-1952.

Elliott, J., Gale, C. R., Parsons, S., Kuh, D., \& Team, H. S. (2014). Neighbourhood cohesion and mental wellbeing among older adults: a mixed methods approach. Social Science \& Medicine, 107, 4451.

Fiske, A., Wetherell, J. L., \& Gatz, M. (2009). Depression in Older Adults. Annual Review of Clinical Psychology, 5, 363-389. doi: 10.1146/annurev.clinpsy.032408.153621

Glass, T. A., \& Balfour, J. L. (2003). Neighborhoods, aging, and functional limitations. In I. Kawachi \& L. F. Berkman (Eds.), Neighborhoods and Health (pp. 303-334). New York, NY, USA: Oxford University Press.

Graif, C., Gladfelter, A. S., \& Matthews, S. A. (2014). Urban Poverty and Neighborhood Effects on Crime: Incorporating Spatial and Network Perspectives. Sociology compass, 8(9), 1140-1155. doi: $10.1111 /$ soc4.12199

Hess, D. B. (2009). Access to Public Transit and Its Infuence on Ridership for Older Adults in Two U.S. Cities. Journal of Transport and Land Use, 2(1), 3-27.

Horner, M. W., Duncan, M. D., Wood, B. S., Valdez-Torres, Y., \& Stansbury, C. (2015). Do aging populations have differential accessibility to activities? Analyzing the spatial structure of social, professional, and business opportunities. Travel Behaviour and Society(0). doi: http://dx.doi.org/10.1016/j.tbs.2015.03.002

Hsieh, C.-C., \& Pugh, M. D. (1993). Poverty, Income Inequality, and Violent Crime: A Meta-Analysis of Recent Aggregate Data Studies. Criminal Justice Review, 18(2), 182-202. doi: doi:10.1177/073401689301800203

Ivey, S. L., Kealey, M., Kurtovich, E., Hunter, R. H., Prohaska, T. R., Bayles, C. M., \& Satariano, W. A. (2015). Neighborhood characteristics and depressive symptoms in an older population. Aging \& mental health, 19(8), 713-722. 
J. Katon, W. (2011). Epidemiology and treatment of depression in patients with chronic medical illness. Dialogues in Clinical Neuroscience, 13(1), 7-23.

Joshi, S., Mooney, S. J., Rundle, A. G., Quinn, J. W., Beard, J. R., \& Cerdá, M. (2017). Pathways from neighborhood poverty to depression among older adults. Health \& Place, 43(Supplement C), 138-143. doi: https://doi.org/10.1016/j.healthplace.2016.12.003

Julien, D., Richard, L., Gauvin, L., \& Kestens, Y. (2012). Neighborhood characteristics and depressive mood among older adults: an integrative review. International Psychogeriatrics, 24(8), 12071225. doi: $10.1017 / \mathrm{S} 1041610211002894$

Kalton, A., Falconer, E., Docherty, J., Alevras, D., Brann, D., \& Johnson, K. (2016). Multi-Agent-Based Simulation of a Complex Ecosystem of Mental Health Care. J Med Syst, 40(2), 1-8.

Karp, F. (2007). Growing older in America: The health and retirement study. : National Institute on Aging, National Institutes of Health, US Department of Health and Human Services. .

Kawachi, I., \& Berkman, L. F. (2001). Social ties and mental health. Journal of Urban Health, 78(3), 458467. doi: 10.1093/jurban/78.3.458

Kochanek, K. D., Murphy, S. L., Xu, J., \& Tejada-Vera, B. (2016). Deaths: Final Data for 2014 National Vital Statistics Reports (Vol. 65).

Luke, D. A., \& Stamatakis, K. A. (2012). Systems Science Methods in Public Health: Dynamics, Networks, and Agents. Annual Review of Public Health, 33(1), 357-376. doi: doi:10.1146/annurevpublhealth-031210-101222

Lynott, J., \& Figueiredo, C. (2011). How the Travel Patterns of Older Adults Are Changing: Highlights from the 2009 National Household Travel Survey: AARP Public Policy Institute.

Lyon, A. R., Maras, M. A., Pate, C. M., Igusa, T., \& Stoep, A. (2016). Modeling the Impact of School-Based Universal Depression Screening on Additional Service Capacity Needs: A System Dynamics Approach. Administration and Policy in Mental Health and Mental Health Services Research, 43(2), 168-188. doi: 10.1007/s10488-015-0628-y

Mair, C., Roux, A. V. D., \& Galea, S. (2008). Are neighbourhood characteristics associated with depressive symptoms? A review of evidence. Journal of Epidemiology and Community Health, 62(11), 940946. doi: 10.1136/jech.2007.066605

Mammen, G., \& Faulkner, G. (2013). Physical Activity and the Prevention of Depression: A Systematic Review of Prospective Studies. American Journal of Preventive Medicine, 45(5), 649-657. doi: http://dx.doi.org/10.1016/j.amepre.2013.08.001

Martin G. Cole, \& Nandini Dendukuri. (2003). Risk Factors for Depression Among Elderly Community Subjects: A Systematic Review and Meta-Analysis. American Journal of Psychiatry, 160(6), 11471156. doi: 10.1176/appi.ajp.160.6.1147

Meeks, T. W., Vahia, I. V., Lavretsky, H., Kulkarni, G., \& Jeste, D. V. (2011). A tune in "a minor" can "b major": A review of epidemiology, illness course, and public health implications of subthreshold depression in older adults. Journal of Affective Disorders, 129(1), 126-142. doi: https://doi.org/10.1016/j.jad.2010.09.015

Mooney, S. J., \& El-Sayed, A. M. (2016). Stigma and the etiology of depression among the obese: An agent-based exploration. Social Science \& Medicine, 148, 1-7. doi: http://doi.org/10.1016/i.socscimed.2015.11.020

Mooney, S. J., \& El-Sayed, A. M. (2016). Stigma and the etiology of depression among the obese: An agent-based exploration. Soc Sci Med, 148, 1-7. doi: 10.1016/j.socscimed.2015.11.020

Musselwhite, C., Holland, C., \& Walker, I. (2015). The role of transport and mobility in the health of older people. Journal of Transport \& Health(0). doi: http://dx.doi.org/10.1016/i.jth.2015.02.001

NHTS. (2017). National Household Travel Survey. from http://nhts.ornl.gov/

Nianogo, R. A., \& Arah, O. A. (2015). Agent-Based Modeling of Noncommunicable Diseases: A Systematic Review. American Journal of Public Health, 105(3), e20-e31. doi: 10.2105/AJPH.2014.302426 
Patten, S. B., Williams, J. V. A., Lavorato, D. H., \& Eliasziw, M. (2009). A longitudinal community study of major depression and physical activity. General Hospital Psychiatry, 31(6), 571-575. doi: http://dx.doi.org/10.1016/i.genhosppsych.2009.08.001

Peck, M. D. (2010). Barriers to Using Fixed-Route Public Transit for Older Adults Mineta Transportation Institude Report: San Jose State University.

Pucher, J., Buehler, R., Merom, D., \& Bauman, A. (2011). Walking and Cycling in the United States, 20012009: Evidence From the National Household Travel Surveys. American Journal of Public Health, AJPH.2010.300067. doi: 10.2105/ajph.2010.300067

Pucher, J., \& Renne, J. L. (2003). Socioeconomics of Urban Travel: Evidence from the 2001 NHTS. Transportation Quarterly, 57(3), 49-77.

Quinn, T. D., Jakicic, J. M., Fertman, C. I., \& Barone Gibbs, B. (2016). Demographic factors, workplace factors and active transportation use in the USA: a secondary analysis of 2009 NHTS data. Journal of Epidemiology and Community Health. doi: 10.1136/jech-2016-207820

The Repast Suite. (2017). from https://repast.github.io/index.html

Reynolds, C. F., Cuijpers, P., Patel, V., Cohen, A., Dias, A., Chowdhary, N., . . Albert, S. M. (2012). Early Intervention to Reduce the Global Health and Economic Burden of Major Depression in Older Adults. Annual Review of Public Health, 33, 123-135. doi: 10.1146/annurev-publhealth-031811124544

Richardson, R., Westley, T., Gariépy, G., Austin, N., \& Nandi, A. (2015). Neighborhood socioeconomic conditions and depression: a systematic review and meta-analysis. Social psychiatry and psychiatric epidemiology, 50(11), 1641-1656.

Rosso, A. L., Auchincloss, A. H., \& Michael, Y. L. (2011). The Urban Built Environment and Mobility in Older Adults: A Comprehensive Review. Journal of Aging Research, 2011. doi: $10.4061 / 2011 / 816106$

Saelens, B. E., \& Handy, S. L. (2008). Built environment correlates of walking: a review. Medicine and Science in Sports and Exercise, 40. doi: 10.1249/MSS.0b013e31817c67a4

Schafer, A., \& Victor, D. G. (2000). The future mobility of the world population. Transportation Research Part A: Policy and Practice, 34(3), 171-205. doi: http://dx.doi.org/10.1016/S09658564(98)00071-8

Steffens, D. C., Fisher, G. G., Langa, K. M., Potter, G. G., \& Plassman, B. L. (2009). Prevalence of depression among older Americans: the Aging, Demographics and Memory Study. International psychogeriatrics / IPA, 21(5), 879-888. doi: 10.1017/S1041610209990044

Thielke, S. M., Diehr, P., \& Unützer, J. (2010). Prevalence, incidence, and persistence of major depressive symptoms in the Cardiovascular Health Study. Aging \& Mental Health, 14(2), 168-176. doi: $10.1080 / 13607860903046537$

Transportation for America. (2011). Aging in Place, Stuck without Options: Fixing the Mobility Crisis Threatening the Baby Boom Generation.

Ulrich, R. S., Simons, R. F., Losito, B. D., Fiorito, E., Miles, M. A., \& Zelson, M. (1991). Stress recovery during exposure to natural and urban environments. Journal of Environmental Psychology, 11(3), 201-230. doi: http://dx.doi.org/10.1016/S0272-4944(05)80184-7

US Census Bureau. (2017). Distribution of Licensed Drivers-2014 by Sex and Percentage in each Age Group \& Relation. from https://www.fhwa.dot.gov/policyinformation/statistics/2014/pdf/dl20.pdf

West, L. A., Cole, S., Goodkind, D., \& He, W. (2014). 65+ in the United States: 2010 Current Population Reports: U.S. CENSUS BUREAU.

Winters, M., Brauer, M., Setton, E., \& Teschke, K. (2010). Built Environment Influences on Healthy Transportation Choices: Bicycling versus Driving. Journal of Urban Health, 87(6), 969-993. doi: 10.1007/s11524-010-9509-6 
1 World Health Organization. (2013). Mental health action plan 2013 - 2020.

2 Yang, Y., Auchincloss, A. H., Rodriguez, D. A., Brown, D. G., Riolo, R., \& Diez-Roux, A. V. (2015). Modeling

3 spatial segregation and travel cost influences on utilitarian walking: Towards policy intervention.

$4 \quad$ Computers, Environment and Urban Systems, 51(0), 59-69. doi:

$5 \quad$ http://dx.doi.org/10.1016/i.compenvurbsys.2015.01.007

6 Yang, Y., Diez Roux, A. V., Auchincloss, A. H., Rodriguez, D. A., \& Brown, D. G. (2011). A Spatial Agent-

$7 \quad$ Based Model for the Simulation of Adults' Daily Walking Within a City. American Journal of

$8 \quad$ Preventive Medicine, 40(3), 353-361. doi: http://dx.doi.org/10.1016/i.amepre.2010.11.017

9 Yuri, M., \& Brenda, W. J. H. P. (2014). Depression in Older Persons with Mobility Limitations. Current

$10 \quad$ Pharmaceutical Design, 20(19), 3114-3118. doi:

11 http://dx.doi.org/10.2174/13816128113196660060

12 Zahavi, Y., \& Talvitie, A. (1980). Regularities in travel time and money expenditures. Transportation

13 Research Record(750), 13-19. 